\title{
Socioeconomic and psychosocial factors influence pain or physical function in Asian patients with knee or hip osteoarthritis
}

\author{
J Thumboo, L-H Chew, S-C Lewin-Koh, for the National Arthritis Foundation and \\ Nanyang Polytechnic, Singapore
}

Ann Rheum Dis 2002;61:1017-1020

\begin{abstract}
Objective: To determine factors influencing pain or physical function in Asian patients with osteoarthritis (OA). Methods: 126 consecutive Chinese (1 10), Malays (two), Indians (10), or other races (four) with knee or hip OA and a median age of 60.5 years were seen at a tertiary referral centre; 103 were women. Subjects underwent a structured assessment including the Short Form-36 (SF-36) bodily pain (BP) and physical functioning (PF) scales and assessing demographic, socioeconomic, psychosocial, and other characteristics. Factors influencing BP or PF were identified using separate multiple linear regression models. Results: The index joint (that is, the most symptomatic joint) was the knee in $118(94 \%)$ and the hip in eight $(6 \%)$ patients. The median duration of pain and limitation of normal activities were three years and one year, respectively. The mean BP and PF scores of 57.7 and 56.2 points for the patients were substantially lower than the expected scores of 79.3 and 80.8 points for the general Singapore population. Multiple regression analysis showed that less pain was associated with a younger age, shorter duration of symptoms, more years of education, working, and Chinese ethnicity. Better physical function was associated with more years of education, less learned helplessness, less bodily pain, and less severe OA.

Conclusions: Socioeconomic status and psychosocial factors, some of which are potentially modifiable, influence pain or physical function in Asian patients with $\mathrm{OA}$ in Singapore.
\end{abstract}

O steoarthritis (OA) of the knees and hips results in significant disability in the general population, largely owing to increased pain and decreased physical function. ${ }^{1}$ However, the degree of pain and disability for any given degree of severity of OA varies widely, with many patients with OA not seeking medical attention, ${ }^{2}$ and with radiographic OA correlating poorly with pain and physical function. ${ }^{3}$ These observations suggest that factors other than severity of disease influence pain and physical function in patients with $\mathrm{OA}^{2}$ These factors include age, ${ }^{14} \mathrm{sex}_{,}{ }^{4}$, marital, ${ }^{4}$ and socioeconomic status, ${ }^{145}$ duration of arthritis, ${ }^{4}$ body mass index, ${ }^{46}$ chronic diseases, ${ }^{4}$ social support, ${ }^{12}$ and psychosocial factors. ${ }^{1}$

To the best of our knowledge, few, if any, studies have assessed the influence of such factors on pain or physical function in Asian subjects with OA. Such studies are needed to determine if a similar paradigm of disability in OA is present in Asian sociocultural contexts, especially as factors influencing disease manifestations are known to vary among ethnic groups. ${ }^{7}$ This study, therefore, aimed at identifying factors that influenced pain or physical function in a multiethnic group of Asian patients with OA.

\section{METHODS \\ Study design and data collection}

This cross sectional, Institutional Review Board approved study assessed English or Chinese speaking Chinese, Malay, or Indian inpatients or outpatients with knee or hip OA attending consecutively over two weeks at Tan Tock Seng Hospital, a tertiary referral hospital in Singapore, an Asian country with an urban population of 3.3 million Chinese, Malays, and Indians (ethnic distribution: $76.8,13.9$, and $7.9 \%$ respectively). Inclusion criteria were $(a)$ knee or hip OA; $(b)$ absence of other forms of arthritis or lower limb conditions causing immobility. Patients with hip or knee OA were studied together as these conditions tend to coexist, and so that our results would be comparable with other studies. ${ }^{38}$ Trained fieldworkers conducted a structured interview and medical record review using a pre-tested data collection form. Subjects answered questions with reference to the most symptomatic knee or hip joint (that is, the index joint). Two trained examiners unaware of the subject data examined patients to grade the severity of OA using a visual analogue scale and to assess the American College of Rheumatology functional status. ${ }^{9}$

\section{Instruments and definitions}

In the Short-Form 36 (SF-36) bodily pain (BP) and physical functioning (PF) scales, ${ }^{10} 11$ higher scores (range 0-100) reflect less pain or better physical functioning, respectively. Higher scores in the Helplessness Subscale indicate more learned helplessness, in which, as a result of adverse past experiences, subjects believe their efforts will be ineffective. ${ }^{12}$ Higher scores in the Family Functioning Measure ${ }^{13}$ reflect better interactions among family members. OA was diagnosed by a rheumatologist or orthopaedic surgeon using clinical and radiographic assessment. Comorbidities were self reported diabetes, hypertension, stroke, or ischaemic heart disease. Ethnicity was that stated in a subject's national registration identification card.

\section{Statistical analyses}

The association of BP or PF scores with possible factors affecting pain or physical function was assessed using Pearson's correlations (table 1) or one way parametric analysis of variance (table 2). Exploratory analysis including all these possible factors was performed (with factors in table 2 coded using dummy variables ${ }^{14}$ ) to identify the best set of predictors of pain or physical function using separate linear regression models with BP and PF scores as outcome variables; a combination of forward stepwise and all possible regression

Abbreviations: $\mathrm{BP}$, bodily pain (SF-36 scale); $\mathrm{OA}$, osteoarthritis; PF, physical functioning (SF-36 scale); SF-36, Short Form-36 Health Survey 
Table 1 Characteristics of study subjects and associations with pain and physical function: Pearson's correlations

\begin{tabular}{|c|c|c|c|}
\hline & \multirow[b]{2}{*}{ Mean (range) } & \multicolumn{2}{|c|}{ Correlation coefficients } \\
\hline & & $\begin{array}{l}\text { Bodily pain } \\
\text { score }\end{array}$ & $\begin{array}{l}\text { Physical } \\
\text { functioning score }\end{array}$ \\
\hline Age (years) & $60.7(33-86)$ & 0.13 & -0.09 \\
\hline Body mass index $\dagger$ & $25.4(14.6-44.0)$ & -0.06 & -0.16 \\
\hline \multicolumn{4}{|l|}{ Duration of symptoms in index joint (years) } \\
\hline Pain & $4.4(0-20)$ & -0.11 & -0.12 \\
\hline Stiffness & $2.9(0-20)$ & -0.17 & -0.17 \\
\hline Limitation of normal activities & $3.1(0-20)$ & $-0.22 * *$ & -0.11 \\
\hline Pain on movement (VAS, mm) & $43.8(0-100)$ & - & $-0.36^{* * *}$ \\
\hline Global assessment of disease severity (VAS, mm) & $23.0(0-98)$ & -0.14 & $-0.32 * * *$ \\
\hline Number of comorbidities $\ddagger$ & $0.85(0-5)$ & 0.07 & 0.08 \\
\hline Family functioning measure score & $57.7(0-100)$ & -0.01 & 0.13 \\
\hline Helplessness subscale score & $15.0(9-23)$ & -0.16 & $-0.29 * * *$ \\
\hline Bodily pain score§ & $57.7(0-100)$ & - & $0.44 * * *$ \\
\hline Physical functioning score & $56.2(0-100)$ & $0.44^{* * *}$ & - \\
\hline \multicolumn{4}{|c|}{$\begin{array}{l}\text { Higher bodily pain scores indicate less pain (see "Methods"). } \\
\text { VAS, visual analogue scale. } \\
\text { "p<0.05; }{ }^{* *} p<0.01 ; ;^{* * *} p<0.001 ; \text { tbody mass index=body weight }(\mathrm{kg}) \text { divided by the square of a } \\
\text { subject's height in metres; } \neq \text { comorbidities were present in } 73 / 126(58 \%) \text { subjects; } \S \text { percentage with } \\
\text { minimum/maximum scores (that is, floor/ceiling effects) }=0.79 / 9.52 \% \text {; } 9 \text { percentage with } \\
\text { minimum/maximum scores (that is, floor/ceiling effects) }=1.59 / 2.38 \% \text {. }\end{array}$} \\
\hline
\end{tabular}

modelling procedures was used, which yields better fitting models than stepwise regression alone. ${ }^{14}$ Questionnaire language may influence PF or BP scores and was assessed by including a language variable (English/Chinese) in the model building process. First order interactions were studied for factors identified in the model building process, and diagnostic tests were performed to confirm that assumptions for linear regression were fulfilled.

\section{RESULTS}

\section{Subject characteristics and SF-36 scores}

Most of the subjects were elderly Chinese women, and the commonest site of OA was at the knee (tables 1 and 2). English and Chinese questionnaires were completed by 59 and 67 subjects, respectively. The subjects' mean BP and PF scores of 57.7 and 56.2, respectively, were substantially lower than the 79.3 and 80.8 points, respectively, expected in the general

Table 2 Characteristics of study subjects and associations with pain and physical function: one way analysis of variance

\begin{tabular}{|c|c|c|c|c|}
\hline & \multirow[b]{2}{*}{ No (\%) } & \multicolumn{3}{|c|}{ Mean score (range) } \\
\hline & & Bodily pain & Physi & functioning \\
\hline \multicolumn{5}{|l|}{ Sex } \\
\hline Male & $23(18)$ & $64.5(31-100)$ & 60.9 & $(15-100)$ \\
\hline $\begin{array}{l}\text { Female } \\
\text { p Value }\end{array}$ & $103(82)$ & $\begin{array}{l}56.2(0-100) \\
0.08\end{array}$ & $\begin{array}{l}55.1 \\
0.29\end{array}$ & $(0-100)$ \\
\hline \multicolumn{5}{|l|}{ Ethnicity } \\
\hline Chinese & $110(87)$ & $59.2(12-100)$ & 55.9 & $(0-100)$ \\
\hline Non-Chinese * & $16(13)$ & $47.3(0-74)$ & 57.8 & $(30-95)$ \\
\hline $\mathrm{p}$ Value & & 0.03 & 0.76 & \\
\hline \multicolumn{5}{|c|}{ Years of education $†$} \\
\hline 0 & $27(21)$ & $53.6(22-74)$ & 42.0 & $(0-90)$ \\
\hline$\geqslant 1$ & 99 (79) & $58.8(0-100)$ & 60.0 & $(10-100)$ \\
\hline $\mathrm{p}$ Value & & 0.24 & 0.00 & \\
\hline \multicolumn{5}{|l|}{ Working } \\
\hline Yes & $45(36)$ & $59.9(12-100)$ & 61.2 & $(0-100)$ \\
\hline No & 81 (64) & $56.5(0-100)$ & 53.4 & $(0-100)$ \\
\hline $\mathrm{p}$ Value & & 0.38 & 0.08 & \\
\hline \multicolumn{5}{|l|}{ Osteoarthritis of } \\
\hline Knees & 122 (97) & $58.0(0-100)$ & 56.4 & $(0-100)$ \\
\hline Hips & $11(9)$ & $52.5(22-74)$ & 55.5 & $(10-85)$ \\
\hline Hands & $20(16)$ & $54.7(22-100)$ & 59.6 & $(0-100)$ \\
\hline p Value & & 0.65 & 0.70 & \\
\hline \multicolumn{5}{|l|}{ Index joint } \\
\hline Knee & $118(94)$ & $58.2(0-100)$ & 56.1 & $(0-100)$ \\
\hline Hip & $8(6)$ & $50.9(22-74)$ & 56.9 & $(10-85)$ \\
\hline $\mathrm{p}$ Value & & 0.33 & 0.93 & \\
\hline \multicolumn{5}{|l|}{ Married } \\
\hline Yes & 95 (75) & $57.1(22-100)$ & 56.3 & $(0-100)$ \\
\hline No & $31(25)$ & $59.6(0-100)$ & 55.7 & $(0-100)$ \\
\hline $\mathrm{p}$ Value & & 0.55 & 0.89 & \\
\hline
\end{tabular}


Table 3 Factors influencing bodily pain: a multiple linear regression model

\begin{tabular}{|c|c|c|c|c|}
\hline Factor & $\begin{array}{l}\text { Coefficient } \\
\text { (ß) }\end{array}$ & $\begin{array}{l}\text { Standard } \\
\text { error }\end{array}$ & t Statistic & $\mathrm{p}$ Value \\
\hline Constant & 44.01 & 5.24 & 8.39 & $<0.0001$ \\
\hline Chinese ethnicity (versus non-Chinese) & 16.73 & 5.28 & 3.17 & 0.002 \\
\hline Duration of limitation in normal activities (per year) & -0.83 & 0.40 & -2.06 & 0.042 \\
\hline Age (years) & -0.02 & 0.41 & -0.04 & 0.966 \\
\hline No education (versus $\geqslant 1$ year of education) & -7.95 & 5.24 & -1.52 & 0.132 \\
\hline Working & 7.03 & 3.89 & 1.81 & 0.073 \\
\hline Interaction: Chinese ethnicity and age & 1.00 & 0.46 & 2.15 & 0.034 \\
\hline Interaction: education * and age & -1.02 & 0.49 & -2.08 & 0.039 \\
\hline \multicolumn{5}{|c|}{$\begin{array}{l}\text { *No education versus } \geqslant 1 \text { year of education. } \\
\text { Higher bodily pain scores indicate less pain (see "Methods"). } \\
\text { Age and education were retained in the model because the presence of statistically significant interaction } \\
\text { terms involving these variables requires this (see ref } 14) \text {. } \\
\text { Model unadjusted } R^{2}=0.22 \text {; adjusted } R^{2}=0.17 ; \mathrm{F} \text { statistic }=4.66(\mathrm{p}<0.0001) \text {. }\end{array}$} \\
\hline
\end{tabular}

Table 4 Factors influencing physical function: a multiple linear regression model

\begin{tabular}{|c|c|c|c|c|}
\hline Factor & $\begin{array}{l}\text { Coefficient } \\
\text { (ß) }\end{array}$ & $\begin{array}{l}\text { Standard } \\
\text { error }\end{array}$ & t Statistic & $\mathrm{p}$ Value \\
\hline Constant & 59.07 & 1.93 & 30.55 & $<0.0001$ \\
\hline No education (versus $\geqslant 1$ year of education) & -10.48 & 4.46 & -2.35 & 0.021 \\
\hline Helplessness subscale score & -1.81 & 0.65 & -2.78 & 0.006 \\
\hline Bodily pain score* & 0.33 & 0.09 & 3.69 & $<0.001$ \\
\hline Global assessment of disease severity (VAS, $\mathrm{mm}$ ) & -0.19 & 0.09 & -2.12 & 0.036 \\
\hline Interaction between bodily pain and education $t$ & 0.77 & 0.27 & 2.86 & 0.005 \\
\hline
\end{tabular}

population (adjusted for age, sex, ethnicity, and questionnaire language). ${ }^{11}$

\section{Factors influencing pain in Asian patients with OA}

All factors significantly associated with BP on univariate analysis (tables 1 and 2) were selected in the modelling process (table 3). Of note, scoring for the BP scale is such that higher scores indicate less bodily pain. Subjects who were younger, working, Chinese, with a shorter duration of limitation in normal activities or with $\geqslant 1$ year of education had less pain. First order interactions were such that in Chinese subjects with $\geqslant 1$ year of education, increasing age was associated with less pain, whereas in Chinese with no education, increasing age was associated with more pain. In non-Chinese subjects, increasing age was associated with increased pain for all subjects, and was more marked in subjects with no education.

\section{Factors influencing physical function in Asian patients with OA}

All factors significantly associated with PF on univariate analysis with the exception of pain on movement (tables 1 and 2 ) were selected in the modelling process (table 4). Subjects with less bodily pain, less severe OA, less learned helplessness, or with one or more years of education had better physical function. First order interactions between BP and education were such that in subjects with no years of education, more pain resulted in a greater reduction in physical function than in subjects with $\geqslant 1$ year of education.

\section{DISCUSSION}

This study found that socioeconomic status and psychosocial factors, as well as ethnicity, demographic, and disease related factors, independently influenced pain or physical function in Asian patients in Singapore with OA. These findings have several implications. Firstly, several factors were associated with differences in PF or BP scores that exceeded five points (suggested as the minimum clinically important difference for
SF-36 scores $\left.^{10}\right)$, and may therefore have a clinically important impact on the health status of patients with OA. As some of these factors (for example, learned helplessness) may be modified, interventions in these areas may reduce pain and improve physical function in such patients. Secondly, our data show that socioeconomic status and psychosocial factors influence pain and functional status in a multiethnic, urban Asian sociocultural context. To the best of our knowledge, this has not been previously demonstrated. Interestingly, the influence of socioeconomic status on physical function was modulated by the degree of pain, highlighting the close relationship among these three domains. Thirdly, our data further highlight the fact that patients with OA in an Asian population, like those in non-Asian populations, have substantially more pain and a lower level of physical functioning than the general population.

Factors influencing pain or physical function in Asians with OA in this study were broadly similar to those identified in studies in non-Asian populations. ${ }^{4-6}$ Modelling restricted to female Chinese subjects (performed because of the small number of male and non-Chinese subjects) yielded similar results to models using the entire study sample. Some previously reported associations (for example, between BP or PF and sex, ${ }^{4}$ body mass index,${ }^{46}$ or marital status ${ }^{4}$ ) were not seen in this study. There are several possible reasons for this. Firstly, specific factors influencing PF or BP may differ among various ethnic groups-for example, black and white Americans with $\mathrm{OA}^{7}$. Secondly, the different instruments used to assess pain or physical function in various studies might have influenced the selection of factors associated with these outcomes. ${ }^{6}$

Ethnicity influenced the degree of pain independently of socioeconomic status in this study (with Chinese showing clinically important differences in BP scores $^{10}$ ), and was modulated by age and educational status, as shown by the interactions involving these variables. Ethnic differences in factors affecting physical function have previously been reported in patients with $\mathrm{OA}^{7}$ Observed ethnic differences in 
BP scores may be related to ethnic differences in unmeasured determinants of pain arising from ethnic differences in culture, identity or minority status ${ }^{15}$ and including genetic, psychosocial, or disease related factors, as seen in patients with cancer. ${ }^{15}$

Study limitations include the cross sectional design, which, as in similar studies, ${ }^{13-6}$ demonstrates association rather than causation. Studying subjects attending a tertiary care hospital and the small numbers of male and non-Chinese subjects limit the generalisability of our results (especially for ethnic differences in pain); however, our data are important in justifying a larger, population based study. Radiographic severity of OA (associated with pain or physical function in some, ${ }^{3}$ but not other studies ${ }^{6}$ ) was not assessed because recent radiographs were not available for some patients, and clinical assessment of OA severity was therefore used as a pragmatic compromise (though the validity and reliability of this approach needs further study).

In conclusion, we found that socioeconomic status and psychosocial factors independently influenced pain or physical function in Asian patients with OA in Singapore, further extending the sociocultural contexts in which this paradigm has been demonstrated. Future studies are needed to determine if this paradigm exists in other Asian sociocultural contexts, and to identify interventions to reduce pain and improve function in this common and disabling condition.

\section{ACKNOWLEDGEMENTS}

We thank Associate Professors HH Chng, KY Fong, R McCartney , and YP Low for their support, students from the Advanced Diploma in Nursing Course (community health, gerontology, medical—surgical, and orthopaedics) for help with fieldwork, and research nurse Thio Szu-tien for able practical assistance.

\section{Authors' affiliations}

J Thumboo, Department of Rheumatology and Immunology, Tan Tock Seng Hospital, Singapore

L-H Chew, School of Health Sciences, Nanyang Polytechnic, Singapore

S-C Lewin-Koh, Department of Statistics and Applied Probability, National University of Singapore, Singapore

Current address of Dr Thumboo: Department of Medicine, National University of Singapore, Singapore.
Correspondence to: Dr J Thumboo, Department of Medicine, National University Hospital, 5 Lower Kent Ridge Road, Singapore 119074

Singapore; mdctj@nus.edu.sg

Accepted 15 April 2002

\section{REFERENCES}

1 Weinberger M, Tierney WM, Booher P, Hiner SL. Social support, stress and functional status in patients with osteoarthritis. Soc Sci Med 1990:30:503-8

2 Hadler NM. Knee pain is the malady-not osteoarthritis. Ann Intern Med 1992; 1 16:598-9

3 Summers MN, Haley WE, Reveille JD, Alarcon GS. Radiographic assessment and psychologic variables as predictors of pain and functional impairment in osteoarthritis of the knee or hip. Arthritis Rheum 1988;31:204-9.

4 Verbrugge LM, Gates DM, Ike RW. Risk factors for disability among U.S. adults with arthritis. J Clin Epidemiol 1991;44:167-82.

5 Hannan MT, Anderson JJ, Pincus T, Felson DT. Educational attainment and osteoarthritis: differential associations with radiographic changes and symptom reporting. J Clin Epidemiol 1992;45:139-47.

6 Creamer P, Lethbridge-Cejku M, Hochberg MC. Determinants of pain severity in knee osteoarthritis: effect of demographic and psychosocial variables using 3 pain measures. J Rheumatol 1999;26:1785-92.

7 Jordan JM, Luta G, Renner JB, Dragomir A, Hochberg MC, Fryer JG. Ethnic differences in self-reported functional status in the rural south: the Johnston County osteoarthritis project. Arthritis Care Res 1996;9:483-91.

8 Hopman-Rock M, Odding E, Hofman A, Kraaimaat FW, Biilsma JW. Physical and psychosocial disability in elderly subjects in relation to pain in the hip and/or knee. J Rheumatol 1996;23:1037-44.

9 Hochberg MC, Chang RW, Dwosh I, Lindsey S, Pincus T, Wolfe F. The American College of Rheumatology 1991 revised criteria for the classification of global functional status in rheumatoid arthritis. Arthritis Rheum 1992;35:498-502.

10 Ware JE Jr, Gandek B. Overview of the SF-36 Health Survey and the International Quality of Life Assessment (IQOLA) Project. J Clin Epidemio 1998:51:903-12

11 Thumboo J, Chan SP, Machin D, Soh CH, Feng PH, Boey ML, et al. Measuring health related quality of life in Singapore: normal values for the English and Chinese SF-36 Health Survey. Ann Acad Med Singapore 2002;31:366-74

12 Thumboo J, Fong KY, Chan SP, Leong KH, Feng PH, Thio ST, et al. The Rheumatology Attitudes Index and its helplessness subscale are valid and reliable measures of learned helplessness in Asian patients with systemic reliable measures of learned helplessness in Asian patient
lupus erythematosus. J Rheumatol 1999;26:1512-17.

13 Thumboo J, Feng PH, Soh CH, Boey ML, Thio ST, Fong KY. Validation of a Chinese version of the Medical Outcomes Study Family and Marital Functioning Measures in patients with SLE. Lupus 2000:9:702-7.

14 Neter J, Kutner MH, Nachsteim CJ, Wasserman W. Applied linear statistical models. 4th ed. Chicago: Irwin, 1996.

15 Meyerowitz BE, Richardson J, Hudson S, Leedham B. Ethnicity and cancer outcomes: behavioral and psychosocial considerations. Psychol Bull 1998;123:47-70. 